\title{
Four-year trends in adiposity and its association with hypertension in serial groups of young adult university students in urban Cameroon: a time-series study
}

Simeon-Pierre Choukem ${ }^{1,2,3^{*}}$, André-Pascal Kengne ${ }^{4}$, Maxime-Leolein Nguefack ${ }^{5}$, Yannick Mboue-Djieka ${ }^{2}$, Daniel Nebongo ${ }^{2}$, Jackson T Guimezap ${ }^{6}$ and Jean Claude Mbanya ${ }^{7,8,9}$

\begin{abstract}
Background: Obesity is a major risk factor for non-communicable diseases (NCDs) and is growing rapidly globally including in sub-Saharan Africa (SSA). We aimed to assess the trend in adiposity markers in Cameroonian university students, and investigated their associations with hypertension.

Methods: From 2009 to 2012, we annually measured weight, height, blood pressure, waist (WC) and hip circumferences, and calculated the body mass index (BMI) and other indices of adiposity in consecutive students aged 18 years or above, during their registration. Time-trends in prevalence of overweight and obesity were estimated, and their associations with prevalent hypertension investigated.

Results: Among the 2726 participants, the overall prevalence of obesity, overweight and obesity combined, and hypertension was 3.5\%, 21.0\% and 6.3\% respectively. From 2009 to 2012, the prevalence of overweight and obesity increased in men only, from $13.1 \%$ to $20.9 \%$ ( $p$-trend $=0.002$ ), whereas prevalent abdominal obesity increased in women only, from $6.5 \%$ to $11.7 \%$ ( $p$-trend $=0.027$ ). The BMI and the WC were independent predictors of hypertension; each $\mathrm{kg} / \mathrm{m}^{2}$ higher BMI was associated with $11 \%$ higher odds of hypertension, and each centimeter higher WC was associated with $9 \%$ higher odds of hypertension.
\end{abstract}

Conclusion: Our results show that overweight and obesity are rapidly increasing in this population of young sub-Saharan African adults, and are contributing to an increasing burden of hypertension.

Keywords: Overweight, Obesity, Hypertension, Trends, Association, Cameroon

\section{Background}

Non-communicable diseases (NCDs) such as cardiovascular diseases, diabetes, hypertension and cancers are growing rapidly globally including in sub-Saharan Africa (SSA) [1-3]. The most effective strategy to tackle these NCDs is to prevent them by targeting their risk factors and their upstream determinants as early as possible in the life course. Obesity is a major risk factor for NCDs and is increasing rapidly. The latest Global burden of

\footnotetext{
*Correspondence: schoukem@gmail.com

'Department of Internal Medicine and Pediatrics, Faculty of Health Sciences, University of Buea, P.O. Box 4856, Douala, Buea, Cameroon

${ }^{2}$ Health and Human Development (2HD) Research Network, Douala,

Cameroon

Full list of author information is available at the end of the article
}

obesity report shows that the global prevalence of overweight/obesity increased between 1980 and 2013 from 28.8 to $36.9 \%$ in men, and from 29.8 to $38.0 \%$ in women [4]. Across West African countries comprising Cameroon, estimations show that the prevalence of combined overweight and obesity in 2013 was $32.6 \%$ in men and $34.5 \%$ in women aged 20 years and above, with the corresponding prevalence in Cameroon being 40.4 and $50.7 \%$ [4]. Moreover, this report also shows that successive cohort in both developed and developing countries seemed to be gaining weight at all ages, with most rapid gains between the ages of 20 and 40 years [4].

Developed countries have used observational studies to establish the time-trends in obesity in order to inform 
preventive measures. The ObEpi survey in France shows that the prevalence of overweight and obesity in adults $\geq 18$ years has risen from $46 \%$ in 2009 to $47 \%$ in 2012 [5]. In the sub-population aged 18 to 34 years, the prevalence of obesity alone increased from $14.4 \%$ in 2009 to $16.3 \%$ in 2012. Concomitantly the waist circumference increased from $94.8 \mathrm{~cm}$ to $95.1 \mathrm{~cm}$ in males and $85.5 \mathrm{~cm}$ to $86.5 \mathrm{~cm}$ in females; the ObEpi survey also showed that compared with people with BMI $<25 \mathrm{~kg} / \mathrm{m} 2$, people with overweight or obesity were 2.3 fold and 3.6 fold more at risk to have hypertension, respectively [5].

These time-trends have been less well assessed in SSA, and data in the global burden of obesity or other noncommunicable diseases are often based on extrapolations. Whether such a rise in overweight and obesity within a short period of time would be seen in SSA is not known, as well as its potential consequences on obesity-related conditions such as hypertension. The aim of this study was to assess the trends in adiposity parameters in Cameroonian university students, and to investigate their potential associations with prevalent hypertension.

\section{Methods}

\section{Study design, participants and setting}

We conducted a time-series study in a private university institute in Douala, the most populous city of Cameroon with an estimated population of 2.45 million inhabitants in 2011. Participants were students who presented for their first registration in the institution. They were either new graduates from high school or were coming from other universities. All students aged 18 years or above were included. Those who refused to provide a written informed consent were excluded. Data collection took place during compulsory health assessment as part of the requirements for registration at the institution. The health package provided to each student included characterization of the adiposity status, measurement of blood pressure (BP) and education on lifestyle measures against obesity, diabetes and hypertension. Students were asked to give their written consent to have their data exploited for research purposes. Pregnant women were excluded from the analysis. The study was approved by the Institutional Ethics Committee of Université des Montagnes.

\section{Data collection}

Data were collected each year for four consecutive years by two doctors, over a period of four weeks (mid-October to mid-November) in 2009, 2010, 2011 and 2012. Doctors collecting the data had been trained for that purpose and used validated methods. Data collected included: the BP, weight (to the nearest $100 \mathrm{~g}$ ), height (to the nearest $0.5 \mathrm{~cm}$ ), waist (WC) and hip (HC) circumferences to the nearest $0.5 \mathrm{~cm}$. The $\mathrm{BP}$ was measured in the morning after
5 min of rest in a sitting position, using an OMRON M3 ${ }^{\circ}$ (OMRON HEALTHCARE Co., Kyoto, Japan) with an appropriate cuff. The weight (in $\mathrm{kg}$ ) was measured with a Camry scale that was recalibrated to zero before each measurement, while participants wearing light clothes and without shoes. The waist circumference was taken at mid distance between the iliac crest, and the hip circumference at the level of the great trochanters. The body mass index (BMI) was calculated as the weight in $\mathrm{kg}$ divided by the square of the height in meter $\left(\mathrm{kg} / \mathrm{m}^{2}\right)$. Other secondary variables included waist-to-hip ratio (WHR) and waist-toheight ratio (WHtR) were calculated by simple division.

Overweight was defined as BMI between 25 and $29.9 \mathrm{~kg} / \mathrm{m}^{2}$, and obesity as BMI $\geq 30 \mathrm{~kg} / \mathrm{m} 2$. Hypertension was defined based on a single measurement, as systolic blood pressure $\geq 140 \mathrm{mmHg}$ and/or diastolic blood pressure $\geq 90 \mathrm{mmHg}$ or current antihypertensive treatment.

\section{Statistical analysis}

Data were analysed with the use of SAS/STAT ${ }^{\circ}$ version 9.1 for Windows (SAS Institute Inc., Cary, NC, USA). Results are presented as counts and percentages, mean and standard deviation (SD). Differences between men and women and across years of study were investigated via chi square tests and equivalents for qualitative variables. Linearity in the trend across years was assessed with the Cochran-Armitage trend test, while the analysis of the variance (ANOVA) and equivalents were used for quantitative variables. Logistic regressions models were used to investigate the baseline characteristics associated with prevalent hypertension. Basic regression models were adjusted for age and sex, while the extended multivariable models also comprised significant predictors in basic models, based on a threshold for significance of $p \leq 0.10$. A $p$-value $<0.05$ was used to characterize statistically significant results.

\section{Results \\ General characteristics of participants}

The total study population was 2726 . The annually included number of participants represented $20.5 \%$ of the total population in $2009,17.2 \%$ in $2010,25.3 \%$ in 2011 , and $37.0 \%$ in 2012 (Table 1). Participant's age ranged from 18 to 38.7 years, with a mean (SD) of 21.8 (2.4) years, and was similar across years of study $(p=0.271)$. Gender distribution significantly differed in proportion between years (Table 1). The overall prevalence of obesity, overweight and obesity combined, and hypertension were $3.5 \%, 21.0$ and $6.3 \%$ respectively (Table 2 ). The overall prevalence of abdominal obesity was $0.5 \%$ in men and $7.8 \%$ in women. 
Table 1 Profile of participants overall and across years of the study

\begin{tabular}{|c|c|c|c|c|c|c|c|}
\hline Variables & Overall & 2009 & 2010 & 2011 & 2012 & $p$-value & $\mathrm{p}$-trend \\
\hline $\mathrm{N}(\%)$ & $2726(100)$ & $559(20.5)$ & $469(17.2)$ & $690(25.3)$ & $1008(37.0)$ & & \\
\hline Men, n (\%) & $1893(69.4)$ & 389 (69.6) & $300(64.0)$ & $504(73.0)$ & $700(69.4)$ & 0.013 & 0.383 \\
\hline Mean age, years & $21.8(2.4)$ & $21.8(2.4)$ & $21.7(2.4)$ & $21.9(2.5)$ & $21.7(2.4)$ & 0.271 & 0.850 \\
\hline Pulse, beats per min & $77(13)$ & $76(13)$ & $79(13)$ & $75(13)$ & $77(14)$ & $<0.0001$ & 0.314 \\
\hline Weight, kg & $67.8(10.6)$ & $67.1(10.2)$ & $67.0(10.9)$ & $67.6(10.0)$ & $68.7(10.9)$ & 0.177 & 0.005 \\
\hline Height, cm & $171(9)$ & $171(9)$ & $171(9)$ & $171(8)$ & $171(9)$ & 0.687 & 0.232 \\
\hline Hip circumference, cm & $96(7)$ & $96(9)$ & $96(8)$ & $94(7)$ & $96(8)$ & $<0.0001$ & $<0.0001$ \\
\hline \multicolumn{8}{|l|}{ Men } \\
\hline N (\%) & $1893(100)$ & $389(20.6)$ & $300(15.9)$ & $504(26.6)$ & $700(36.9)$ & & \\
\hline Mean age, years & $21.9(2.5)$ & $22.0(2.5)$ & $21.9(2.5)$ & $22.1(2.6)$ & $21.8(2.4)$ & 0.166 & 0.420 \\
\hline Pulse, beats per min & $74(13)$ & $74(12)$ & $77(13)$ & $73(12)$ & $74(13)$ & 0.0004 & 0.355 \\
\hline Weight, kg & $69.8(9.4)$ & $68.6(8.9)$ & $69.9(9.7)$ & $69.3(9.3)$ & 70.7 (9.6) & 0.002 & 0.288 \\
\hline Height, cm & $174.4(7.0)$ & $174(7)$ & $175(7)$ & $174.2(6.6)$ & $174.5(7.0)$ & 0.130 & 0.618 \\
\hline Hip circumference, $\mathrm{cm}$ & $94.4(6.9)$ & $94.5(7.5)$ & 95.4 (6.6) & $93.2(5.9)$ & $94.8(7.1)$ & $<0.0001$ & 0.004 \\
\hline \multicolumn{8}{|l|}{ Women } \\
\hline N (\%) & $833(100)$ & $170(20.4)$ & $169(20.3)$ & $186(22.3)$ & $308(37.0)$ & & \\
\hline Mean age, years & $21.4(2.3)$ & $21.6(2.3)$ & $21.4(2.0)$ & $21.3(2.1)$ & $21.4(2.5)$ & 0.626 & 0.186 \\
\hline Pulse, beats per min & $83(13)$ & $82(12)$ & $83(12)$ & $82(14)$ & $85(13)$ & 0.098 & 0.818 \\
\hline Weight, kg & $63.4(11.7)$ & $63.6(12.1)$ & $61.9(11.1)$ & $63.2(10.4)$ & $64.2(12.4)$ & 0.236 & 0.767 \\
\hline Height, cm & $163.7(7.2)$ & $163.7(7.2)$ & $163.9(6.0)$ & $164.0(7.2)$ & $163.3(7.7)$ & 0.773 & 0.769 \\
\hline Hip circumference, cm & $98.8(9.4)$ & $100.6(9.9)$ & $98.3(9.0)$ & $97.6(8.2)$ & $98.8(10.0)$ & 0.018 & 0.002 \\
\hline
\end{tabular}

Trends in measures of adiposity

Over four years in the whole population, the prevalence of overweight and obesity combined, abdominal obesity, and the mean WHR rose significantly, whereas the mean waist circumference and WHtR ratio remained stable (Table 2). In men, there was a linear rise in the prevalence of overweight/obesity and the mean WHR, but not in the prevalence of abdominal obesity; in women, the prevalence of abdominal obesity and WHR rose linearly, but not the prevalence of overweight/obesity (Table 3).

\section{Trends in blood pressure}

Systolic blood pressure fluctuated by $3 \mathrm{mmHg}$ in men with a decreasing trend whereas it remained stable in

Table 2 Trends in adiposity and blood pressure parameters in the whole population

\begin{tabular}{|c|c|c|c|c|c|c|c|c|}
\hline Variables & Overall & 2009 & 2010 & 2011 & 2012 & $p$-value & $p$-trend & p year*gender \\
\hline N (\%) & $2726(100)$ & $559(20.5)$ & $469(17.2)$ & $690(25.3)$ & $1008(37.0)$ & & & \\
\hline SBP, mmHg) & $118(12)$ & $119(11)$ & $118(11)$ & $117(13)$ & $118(13)$ & 0.008 & 0.0007 & 0.695 \\
\hline $\mathrm{DBP} \mathrm{mmHg}$ & $70(10)$ & $72(9)$ & $72(10)$ & $69(10)$ & $70(10)$ & $<0.0001$ & $<0.0001$ & 0.841 \\
\hline Hypertension, n (\%) & $172(6.3)$ & $33(5.9)$ & $26(5.6)$ & $36(5.2)$ & $77(7.6)$ & 0.170 & 0.141 & 0.430 \\
\hline $\mathrm{BMI}, \mathrm{kg} / \mathrm{m}^{2}$ & $23.1(3.3)$ & $23.0(3.3)$ & $22.9(3.2)$ & $23.0(2.9)$ & $23.5(3.5)$ & 0.0009 & 0.965 & 0.306 \\
\hline Obesity, n (\%) & $95(3.5)$ & $17(3.0)$ & $14(3.0)$ & $15(2.2)$ & $49(4.9)$ & 0.019 & 0.054 & 0.500 \\
\hline Overweight and obesity, n (\%) & $571(21.0)$ & $95(17.0)$ & $96(20.5)$ & $131(19.0)$ & $249(24.7)$ & 0.001 & 0.0005 & 0.832 \\
\hline Waist circumference, cm & $76(7)$ & $76(7)$ & $75(7)$ & $76(6)$ & $76(8)$ & 0.095 & 0.975 & 0.170 \\
\hline Abdominal obesity, n (\%) & $73(2.7)$ & $12(2.2)$ & $10(2.3)$ & $11(1.6)$ & $40(4.0)$ & 0.016 & 0.032 & 0.601 \\
\hline Hip circumference, cm & $96(7)$ & $96(9)$ & $96(8)$ & $94(7)$ & $96(8)$ & $<0.0001$ & $<0.0001$ & 0.021 \\
\hline WHR, $\mathrm{cm}$ & $0.79(0.05)$ & $0.79(0.05)$ & $0.78(0.05)$ & $0.81(0.04)$ & $0.79(0.06)$ & $<0.0001$ & $<0.0001$ & $<0.0001$ \\
\hline $\mathrm{WH} t \mathrm{R}, \mathrm{cm}$ & $0.44(0.05)$ & $0.44(0.04)$ & $0.44(0.04)$ & $0.44(0.04)$ & $0.44(0.05)$ & 0.177 & 0.513 & 0.096 \\
\hline
\end{tabular}


Table 3 Trends in adiposity and blood pressure parameters by gender

\begin{tabular}{|c|c|c|c|c|c|c|c|}
\hline Variables & Overall & 2009 & 2010 & 2011 & 2012 & $p$-value & $\mathrm{p}$-trend \\
\hline Men, N (\%) & $1893(100)$ & $389(20.6)$ & $300(15.9)$ & $504(26.6)$ & $700(36.9)$ & & \\
\hline $\mathrm{SBP}, \mathrm{mmHg}$ & $120(12)$ & $121(10)$ & $120(11)$ & $118(12)$ & $120(13)$ & 0.003 & 0.0002 \\
\hline $\mathrm{DBP}, \mathrm{mmHg}$ & $70(10)$ & $72(9)$ & $72(10)$ & $69(10)$ & $70(10)$ & $<0.0001$ & $<0.0001$ \\
\hline Hypertension, n (\%) & $133(7.0)$ & $22(5.7)$ & $20(6.7)$ & $30(5.9)$ & $61(8.7)$ & 0.160 & 0.063 \\
\hline $\mathrm{BMI}, \mathrm{kg} / \mathrm{m}^{2}$ & $22.9(2.8)$ & $22.7(2.9)$ & $22.8(2.8)$ & $22.8(2.6)$ & $23.2(2.9)$ & 0.007 & 0.501 \\
\hline Obesity, n (\%) & $39(2.1)$ & $6(1.5)$ & $7(2.3)$ & $8(1.6)$ & $18(2.6)$ & 0.551 & 0.336 \\
\hline Overweight and obesity, n (\%) & $332(17.5)$ & $51(13.1)$ & $51(17.0)$ & $84(16.7)$ & $146(20.9)$ & 0.012 & 0.002 \\
\hline Waist circumference, cm & $76.1(6.5)$ & $76.5(5.8)$ & $75.9(6.3)$ & $76.3(5.6)$ & $75.8(7.4)$ & 0.320 & 0.639 \\
\hline Abdominal obesity, n (\%) & $9(0.5)$ & $1(0.3)$ & $1(0.3)$ & $3(0.6)$ & $4(0.6)$ & 0.843 & 0.429 \\
\hline Hip circumference, cm & $94.4(6.9)$ & $94.5(7.5)$ & $95.4(6.6)$ & $93.2(5.9)$ & $94.8(7.1)$ & $<0.0001$ & 0.004 \\
\hline WHR & $0.81(0.05)$ & $0.81(0.04)$ & $0.79(0.04)$ & $0.82(0.04)$ & $0.80(0.06)$ & $<0.0001$ & 0.011 \\
\hline $\mathrm{WH} t \mathrm{R}$ & $0.44(0.04)$ & $0.44(0.04)$ & $0.43(0.04)$ & $0.44(0.03)$ & $0.43(0.04)$ & 0.065 & 0.424 \\
\hline Women, N (\%) & $833(100)$ & $170(20.4)$ & $169(20.3)$ & $186(22.3)$ & $308(37.0)$ & & \\
\hline $\mathrm{SBP}, \mathrm{mmHg}$ & $113(12)$ & $114(11)$ & $114(11)$ & $113(14)$ & $113(13)$ & 0.565 & 0.241 \\
\hline $\mathrm{DBP}, \mathrm{mmHg}$ & $70(10)$ & $71(10)$ & $72(9)$ & $69(10)$ & $70(10)$ & 0.007 & 0.009 \\
\hline Hypertension, n (\%) & $39(4.7)$ & $11(6.5)$ & $6(3.6)$ & $6(3.2)$ & $16(5.2)$ & 0.426 & 0.700 \\
\hline $\mathrm{BMI}, \mathrm{kg} / \mathrm{m}^{2}$ & $23.7(4.1)$ & $23.7(4.1)$ & $23.0(3.9)$ & $23.5(3.6)$ & $24.1(4.6)$ & 0.057 & 0.675 \\
\hline Obesity, n (\%) & $56(6.7)$ & $11(6.5)$ & $7(4.2)$ & $7(3.8)$ & $31(10.1)$ & 0.020 & 0.064 \\
\hline Overweight and obesity, n (\%) & $239(28.7)$ & $44(25.9)$ & $45(26.8)$ & $47(25.3)$ & $103(33.4)$ & 0.144 & 0.068 \\
\hline Waist circumference, cm & $75.1(8.8)$ & $75.2(8.8)$ & $73.7(8.2)$ & 75.5 (7.6) & $75.6(9.7)$ & 0.149 & 0.709 \\
\hline Abdominal obesity, n (\%) & $64(7.8)$ & $11(6.5)$ & $9(5.6)$ & $8(4.3)$ & $36(11.7)$ & 0.011 & 0.027 \\
\hline Hip circumference, cm & $98.8(9.4)$ & $100.6(9.9)$ & $98.3(9.0)$ & $97.6(8.2)$ & $98.8(10.0)$ & 0.018 & 0.002 \\
\hline WHR & $0.76(0.05)$ & $0.75(0.05)$ & $0.75(0.05)$ & $0.77(0.05)$ & $0.76(0.05)$ & $<0.0001$ & $<0.0001$ \\
\hline WHtR & $0.46(0.05)$ & $0.46(0.05)$ & $0.45(0.05)$ & $0.46(0.05)$ & $0.46(0.06)$ & 0.108 & 0.764 \\
\hline
\end{tabular}

Data are presented as mean (standard deviation), unless indicated otherwise; DBP diastolic blood pressure, SBP, systolic blood pressure, $W H R$, waist-to-hip ratio, WHtR, waist-to-height ratio

women (Table 3). Diastolic blood pressure fluctuated by $3 \mathrm{mmHg}$ in both genders, with a decreasing trend (Table 3). The prevalence of hypertension remained stable over four years in both genders (Table 3).

\section{Adiposity variables and prediction of hypertension}

In the basic model, all parameters of adiposity were significant predictors of prevalent hypertension, except the WHR (Table 4). In the multivariate models, the BMI and the WC were independent predictors of hypertension; each $1 \mathrm{~kg} / \mathrm{m}^{2}$ increase in BMI was associated with $11 \%$ increase in the prevalence of hypertension, and each $1 \mathrm{~cm}$ increase in WC was associated with $9 \%$ rise in the prevalence of hypertension (Table 4).

\section{Discussion}

Over a period of four years in young adults aged 18 to 39 years in urban Cameroon, our data show a rise in the prevalence of combined overweight and obesity in men from $13.9 \%$ in 2009 to $20.1 \%$ in 2012 , and a rise in the prevalence of abdominal obesity in women from $6.5 \%$ in 2009 to $11.7 \%$ in 2012 . We also show that the BMI and the WC are independent predictors of prevalent hypertension in this population.

Reports on adults above 20 years of age in SSA over the past decades have shown high burden of overweight, obesity and hypertension [6-8], as well as a worsening of obesity burden over time [9]. As the central component of the metabolic syndrome, abdominal obesity tends to aggregate with hypertension and other cardiometabolic risk factors, and is also highly prevalent in SSA [10].

Preparedness to tackle obesity requires data on its burden in younger age groups (where interventions are more likely to yield benefits), as well as data on trends. The Global burden of obesity report shows that successive cohort from 1980 to 2013 in both developed and developing countries tend to gain weight at all ages, with most rapid weight gains occurring between the ages of 20 and 40 years [4]. To that end, developed countries have assessed the trends. In the age group between 20 
Table 4 Age, sex and year of study adjusted predictors of hypertension from logistic regression models

\begin{tabular}{|c|c|c|c|c|}
\hline \multirow[t]{2}{*}{ Variable } & \multicolumn{2}{|l|}{ Basic models } & \multicolumn{2}{|c|}{ Multivariable models } \\
\hline & OR $(95 \% \mathrm{Cl})$ & $p$-value & $\mathrm{aOR}(95 \% \mathrm{Cl})$ & $p$-value \\
\hline Age, per year & $1.00(0.94-1.07)$ & 0.918 & $0.99(0.93-1.06)$ & 0.770 \\
\hline Sex (men) & $1.52(1.05-2.19)$ & 0.027 & $1.14(0.73-1.78)$ & 0.559 \\
\hline Year & & 0.163 & & 0.300 \\
\hline 2009 & 1 (reference) & & 1 (reference) & \\
\hline 2010 & $0.92(0.54-1.59)$ & & $0.89(0.52-1.55)$ & \\
\hline 2011 & $0.86(0.53-1.39)$ & & $0.84(0.51-1.37)$ & \\
\hline 2012 & $1.31(0.86-1.99)$ & & $1.21(0.79-1.86)$ & \\
\hline BMI (per kg/m2) & $1.10(1.06-1.14)$ & $<0.0001$ & $1.11(1.02-1.20)$ & 0.013 \\
\hline Obesity & $2.74(1.47-5.12)$ & 0.0015 & & \\
\hline Obesity or overweight & $2.03(1.45-2.86)$ & $<0.0001$ & & \\
\hline Waist circumference (per cm) & $1.04(1.03-1.06)$ & $<0.0001$ & $1.09(1.04-1.15)$ & 0.0004 \\
\hline Abdominal obesity & $4.30(2.15-8.63)$ & $<0.0001$ & & \\
\hline Hip circumference & $1.05(1.03-1.07)$ & $<0.0001$ & & \\
\hline WHR & $1.64(0.08-33.09)$ & 0.747 & & \\
\hline
\end{tabular}

$\mathrm{Cl}$, confidence interval, $a \mathrm{OR}$, adjusted odd ratio, WHR, waist-to-hip ratio, $B M I$, body mass index

and 39 years in the USA, the prevalence of obesity alone increase from $23.7 \%$ in $1999-2000$ to $27.5 \%$ in $2007-$ 2008 in men and from 28.4 to $34.0 \%$ in women during the same periods, respectively [11]. In France, data from the ObEpi survey show that the prevalence of overweight and obesity combined in adults $\geq 18$ years rose from $46 \%$ in 2009 to $47 \%$ in 2012 [5]. Concomitantly the waist circumference increased from 94.8 in $2009 \mathrm{~cm}$ to 95.1 in $2012 \mathrm{~cm}$ in males and $85.5 \mathrm{~cm}$ to $86.5 \mathrm{~cm}$ in females. In the sub-population aged 18 to 34 years, the prevalence of obesity alone increased from $14.4 \%$ in 2009 to $16.3 \%$ in 2012.

In SSA, very few studies have focused on these younger adult age groups or have evaluated the time-trends. Data collected in 2004 in Uganda report overall prevalence of 10.4 and $2.3 \%$ of overweight and obesity respectively, in young adults aged 18 to 30 years [12]. Unhealthy diet and sedentary lifestyle that accompany the process of epidemiologic transition are the likely explanations for these trends in both developed and developing countries [1].

Early descriptions on the clustering of obesity with hypertension and other cardiovascular risk factors in children, adolescents and young adults emerged in the 1980s in the USA [13]. We found in our study that the $\mathrm{BMI}$ and the WC were strong predictors of prevalent hypertension; each $1 \mathrm{~kg} / \mathrm{m}^{2}$ increase in BMI was associated with $11 \%$ increase in the prevalence of hypertension, and each $1 \mathrm{~cm}$ increase in WC was associated with 9\% rise in the prevalence of hypertension. In the ObEpi survey in France, people with overweight or obesity were respectively 2.3 times and 3.6 more likely to have hypertension compared with people with BMI $<25 \mathrm{~kg} /$ m2 [5]. In 1368 adults urban dwellers aged 18 to 88 years in Nigeria with a prevalence of overweight, obesity and hypertension of $32.7 \%, 22.2$ and $33.3 \%$, Amira et al. showed that overweight and obesity were associated with 1.45 and 2.59 odds of prevalent hypertension [14]. In 600 university students aged between 18 and 24 years in Bengal, India, the prevalence of hypertension and combined overweight and obesity were 13 and $35.5 \%$ respectively; in this young population, overweight and obesity were associated with higher rates of hypertension [15]. Overall, the results of our study are congruent with observations made elsewhere in developing and developed countries.

Many potential mechanisms have been proposed to explain the role of obesity in the development of hypertension. These include amongst others: activation of the sympathetic nervous system, sodium retention as a results of increased renal tubular reabsorption, and increased renin-angiotensin-aldosterone system activity [16].

We acknowledge the following potential limitations of our study: it took place in a single centre, and participants were not randomly selected. The results may not therefore apply to the general population of young adults. However, these results indicate a clear picture of the burden of overweight and obesity in a young adults population of Cameroon and their role as major risk factor for hypertension; further, they provide trends that are close to those reported in developed countries, and which will be used as a basis for projections. We also could not measure the blood pressure twice as recommended. Lastly, we lack data on some important 
cardiovascular risk factors we could account for in logistic regressions such as physical activity, diet and sodium intake in particular, and family history of hypertension.

\section{Conclusion}

In this population of young adults of Cameroon, overweight and obesity in men and abdominal obesity in women increase in burden with time. This increase appears as early driving forces for hypertension in this population, and should be targeted early in life so as to curb the increasing burden of hypertension. These results forecast a worsening of cardiovascular diseases especially in women, and call for more aggressive prevention policy against obesity in Cameroon.

\section{Abbreviations}

BMI: Body mass index; BP: Blood pressure; HC: Hip circumference; NCDs: Non-communicable diseases; SSA: Sub Saharan Africa; WC: Waist circumference; WHR: Waist-to-hip ratio; WHtR: Waist-to-height ratio

\section{Acknowledgements}

We are grateful to all participants for accepting to take part in this study. The 2HD Research Network is supported by a Cruddas Link Fellowship (SPC), Tseu Medical Institute, Harris Manchester College, University of Oxford, UK.

\section{Funding}

This work did not receive any funding.

\section{Availability of data and materials}

The datasets generated during and/or analyzed during the current study are not publicly available -because some secondary manuscripts are still being written- but are available from the corresponding author on reasonable request.

\section{Authors' contributions}

Study concept and design: SPC, APK, MLN, YMD, DN, JTG, JCM. Acquisition of data: SPC, MLN, YMD, DN. Data interpretation and analysis: SPC, APK, MLN, JTG, JCM. Manuscript drafting: SPC, APK. Manuscript revisions: SPC, APK, MLN, YMD, DN, JTG, JCM. All authors approved the final manuscript.

\section{Competing interests}

The authors declare that they have no competing interests.

\section{Consent for publication}

Not applicable.

\section{Ethics approval and consent to participate}

Ethical approval was obtained from the Institutional Ethics Committee of Université des Montagnes ( $N^{\circ}$ 2014/75/UdM//PR/CAB/CIE). Informed written consent was obtained from each participant. The study was performed according to the Declaration of Helsinki.

\section{Publisher's Note}

Springer Nature remains neutral with regard to jurisdictional claims in published maps and institutional affiliations.

\footnotetext{
Author details

'Department of Internal Medicine and Pediatrics, Faculty of Health Sciences, University of Buea, P.O. Box 4856, Douala, Buea, Cameroon. ${ }^{2}$ Health and Human Development (2HD) Research Network, Douala, Cameroon. ${ }^{3}$ Diabetes and Endocrine Unit, Department of Internal Medicine, Douala General Hospital, Douala, Cameroon. ${ }^{4}$ South African Medical Research Council, University of Cape Town, Cape Town, South Africa. ${ }^{5}$ Higher Institute of Health Sciences, Université des Montagnes, Bangangte, Cameroon. ${ }^{6}$ University of Montreal, Montreal, QC, Canada. ${ }^{7}$ National Center of Obesity, Diabetes and Endocrinology Yaoundé Central Hospital, Yaoundé, Cameroon. ${ }^{8}$ Laboratory of molecular and metabolic medicine, Biotechnology Center,
}

University of Yaoundé 1, Yaoundé, Cameroon. ${ }^{9}$ Department of Internal Medicine and Subspecialties, Faculty of Medicine and Biomedical Sciences, University of Yaoundé 1, Yaoundé, Cameroon.

Received: 4 January 2017 Accepted: 17 May 2017

Published online: 23 May 2017

\section{References}

1. Yusuf S, Reddy S, Ounpuu S, Anand S. Global burden of cardiovascular diseases: part l: general considerations, the epidemiologic transition, risk factors, and impact of urbanization. Circulation. 2001:104:2746-53.

2. Kearney PM, Whelton M, Reynolds K, Muntner P, Whelton PK, He J. Global burden of hypertension: analysis of worldwide data. Lancet. 2005;365:217-23.

3. International Diabetes Federation. IDF Diabetes Atlas seventh edition [Internet]. 2016. Available from: http://www.idf.org/idf-diabetes-atlasseventh-edition. Accessed 19 May 2017.

4. Ng M, Fleming T, Robinson M, Thomson B, Graetz N, Margono C, et al. Global, regional, and national prevalence of overweight and obesity in children and adults during 1980-2013: a systematic analysis for the global burden of disease study 2013. Lancet. 2014:384:766-81.

5. Eschwege E, Charles MA, Basdevant A, Moisan C. ObEpi: Enquête épidémiologique nationale sur le surpoids et l'obésité. Institut Roche de l'obésité, INSERM, Kantar-Health; 2012 p. 57. Report No.: 16.

6. Kengne AP, Awah PK, Fezeu L, Mbanya JC. The burden of high blood pressure and related risk factors in urban sub-Saharan Africa: evidences from Douala in Cameroon. Afr Health Sci. 2007:7:38-44.

7. Kamadjeu RM, Edwards R, Atanga JS, Kiawi EC, Unwin N, Mbanya J-C. Anthropometry measures and prevalence of obesity in the urban adult population of Cameroon: an update from the Cameroon burden of diabetes baseline survey. BMC Public Health. 2006;6:228.

8. Dzudie A, Kengne AP, Muna WFT, Ba H, Menanga A, Kouam Kouam C, et al. Prevalence, awareness, treatment and control of hypertension in a selfselected sub-Saharan African urban population: a cross-sectional study. BMJ Open. 2012;2

9. Fezeu LK, Assah FK, Balkau B, Mbanya DS, Kengne A-P, Awah PK, et al. Tenyear changes in central obesity and BMI in rural and urban Cameroon. Obes Silver Spring Md. 2008:16:1144-7.

10. Fezeu L, Balkau B, Kengne A-P, Sobngwi E, Mbanya J-C. Metabolic syndrome in a sub-Saharan African setting: central obesity may be the key determinant. Atherosclerosis. 2007;193:70-6.

11. Flegal KM, Carroll MD, Ogden CL, Curtin LR. Prevalence and trends in obesity among US adults, 1999-2008. JAMA. 2010;303:235-41.

12. Baalwa J, Byarugaba BB, Kabagambe EK, Kabagambe KE, Otim AM. Prevalence of overweight and obesity in young adults in Uganda. Afr Health Sci. 2010;10:367-73.

13. Smoak CG, Burke GL, Webber LS, Harsha DW, Srinivasan SR, Berenson GS. Relation of obesity to clustering of cardiovascular disease risk factors in children and young adults. The Bogalusa heart study. Am. J. Epidemiology. 1987;125:364-72.

14. Amira CO, Sukunbi DO, Sukunbi A. The prevalence of obesity and its relationship with hypertension in an urban community: data from world kidney day screening programme. Int J Med Biomed Res. 2012:1:104-10.

15. Das P, Basu M, Chowdhury K, Mallik S, Dhar G, Biswas A. Observational assessment and correlates to blood pressure of future physicians of Bengal. Niger J Clin Pract. 2013:16:433-8.

16. Kotsis V, Stabouli S, Papakatsika S, Rizos Z, Parati G. Mechanisms of obesityinduced hypertension. Hypertens. Res Off J Jpn Soc Hypertens. 2010;33:386-93. 